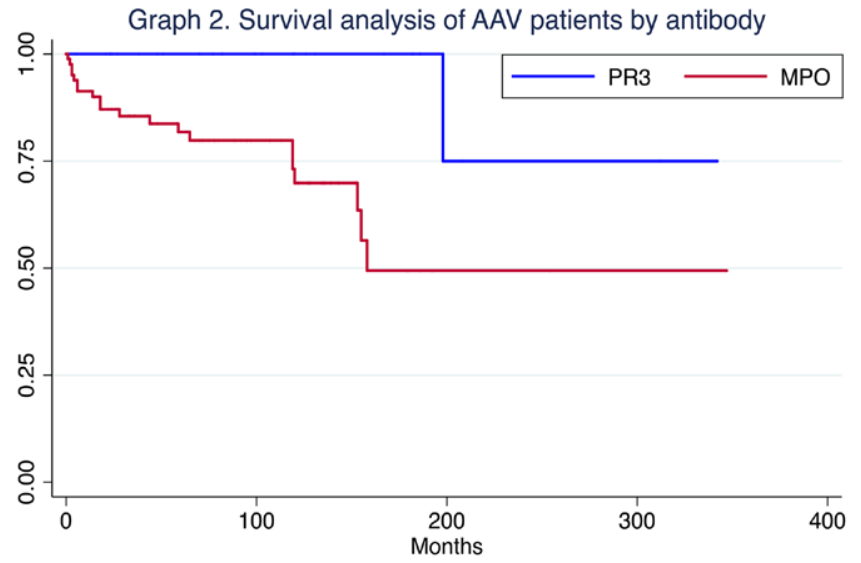

Log-rank $\mathrm{D}=0.008$

patients. When antibody specificity was compared, differences on organ-specific manifestations were less clear than between clinical phenotypes (GPA vs. MPA), and were only seen in ENT/ocular involvement (more frequent in PR3 than in MPO patients) and in muscle biopsies disclosing vasculitis (more frequent in MPO than in PR3 patients). GPA and PR3 patients presented more frequent relapsing disease than MPA and MPO patients, respectively (GPA 60\% vs. MPA $36 \% ; p=0.018$ / PR3 $60 \%$ vs. MPO $41 \% ; p=0.094)$. While GPA tended to have a better survival rate than MPA patients ( $p=0.066$ ) (Graph1), the MPO-associated disease (GPA or MPA) had clearly worse survival prognosis than PR3-AAV $(p=0.008)$ (Graph2), similarly to what occurred in GPA-MPO (compared with GPA-PR3).

Conclusion: A high proportion of GPA patients with MPO-ANCA (45\%) is observed in our series. GPA is associated with a more frequent relapsing disease than MPA. MPA and presence of MPO were more frequent in females and older patients. Clinical features were similar in GPA patients with PR3 or MPO. The presence of MPO (in GPA or MPA) seems to be the main factor associated with mortality in AAV.

References:

[1] Robson JC, Grayson PC, Ponte C, et al. Draft classification criteria for the ANCA associated vasculitides. Ann Rheum Dis 2018;77 (suppl 2):60-1.

Disclosure of Interests: João Fernandes Serodio: None declared, Sergio Prieto-González: None declared, Georgina Espígol-Frigolé: None declared, Marco Alba: None declared, Javier Marco-Hernández: None declared, Maria C. Cid Grant/research support from: Kiniksa Pharmaceuticals, Consultant of: Janssen, Abbvie, Roche, GSK, Speakers bureau: Vifor, José Hernández-Rodríguez: None declared

DOI: 10.1136/annrheumdis-2020-eular.4318

\section{AB0476 \\ GIANT CELL ARTERITIS: A DISEASE WITH DIFFERENT SUBSETS}

E. Fernández ${ }^{1}$, I. Monjo ${ }^{1}$, G. Bonilla ${ }^{1}$, D. Peiteado ${ }^{1}$, C. Plasencia ${ }^{1}$, A. Balsa ${ }^{1}$, E. De Miguel'. ' La Paz University Hospital, Rheumatology, Madrid, Spain

Background: Giant cell arteritis (GCA) is the most common form of autoimmune vasculitis in the elderly. Some evidence indicates that GCA is a heterogeneous disease in terms of symptoms, immune pathology and response to treatment ${ }^{1}$. Objectives: To analyze whether the identification by image of cranial vessels (VC) or large vessels (VG) involvement allows to characterize different clinical subsets of the disease.

Methods: Descriptive observational study of the last 87 consecutive patients with a new diagnosis of GCA in our hospital. All patients had a CV and LV CDUS exam that included axillary, subclavian, vertebral and carotid arteries or a Positron Emission Tomography (PET-CT). The OMERACT (Outcome Measures in Rheumatology) definitions of halo sign were used for ultrasound diagnosis and IMT limits were established as $\geq 0.34 \mathrm{~mm}$ for superficial temporal arteries and $\geq 1 \mathrm{~mm}$ for axillary, subclavian and carotid arteries; a clear halo sign was used in the vertebral arteries. The radiologist's report and the liver/vascular wall index were used for the definition of positive PET-CT. The medical records of these patients were reviewed and their demographic, clinical and laboratory data were compared between the different patterns of GCA. The statistical significance limit was set at $P<0.05$. Statistical analyses were performed by using SPSS version 25 .

Results: Out of 198 patients with suspected GCA who underwent a CDUS or PET-CT between November 2016 and November 2019, 87 were diagnosed of GCA. Three different patterns were detected: 44 patients (50.6\%) had an exclusive cranial pattern, $31(35.6 \%)$ had a mixed pattern with involvement of both $\mathrm{CV}$ and LV and $12(13.8 \%)$ had an exclusive large vessel pattern. The differences between these 3 subsets are shown in table 1. Patients with a LV pattern had more fever and polymyalgia rheumatica than patients with CV involvement and fewer ischemic visual disturbances than those with mixed pattern, reaching statistical significance. In addition, they tended to have fewer other ischemic symptoms (headache, jaw claudication) and more general symptoms than patterns with CV involvement. Regarding laboratory values, the erythrocyte sedimentation rate was significantly higher in the exclusive $\mathrm{CV}$ involvement group and lower in those with only LV involvement.

Table 1. Characteristics of the patients with the different patterns

\begin{tabular}{|c|c|c|c|c|}
\hline & $\begin{array}{l}\text { Cranial pattern (n } \\
\quad=44 ; 50.6 \%)\end{array}$ & $\begin{array}{l}\text { Mixed pattern } \\
(n=31 ; 35.6 \%)\end{array}$ & $\begin{array}{c}\text { Large vessel } \\
\text { pattern } \\
(n=12 ; 13.8 \%)\end{array}$ & $\mathrm{p}$-value \\
\hline Age, years (mean, SD) & $78 \pm 7$ & $76 \pm 7$ & $74 \pm 11$ & 0.291 \\
\hline Male sex & $12(27.3 \%)$ & $14(45.2 \%)$ & $5(41.6 \%)$ & 0.252 \\
\hline ESR, $\mathrm{mm} / \mathrm{h}$ (mean, SD) & $78.7 \pm 33.7$ & $63.9 \pm 33.0$ & $52.1 \pm 33.5$ & $0.031^{*}$ \\
\hline CRP, mg/L (mean, SD) & $55.8 \pm 46.6$ & $68.3 \pm 63.6$ & $85.9 \pm 89.3$ & 0.801 \\
\hline Headache & $36(81.8 \%)$ & $25(80.6 \%)$ & $8(66.6 \%)$ & 0.704 \\
\hline Jaw claudication & $12(27.3 \%)$ & $5(16.1 \%)$ & $1(8.3 \%)$ & 0.249 \\
\hline $\begin{array}{l}\text { Ischemic visual } \\
\text { disturbances }\end{array}$ & $9(20.4 \%)$ & $11(35.5 \%)$ & $0(0 \%)$ & $0.041^{\#}$ \\
\hline PMR & $18(40.9 \%)$ & $13(41.9 \%)$ & $8(66.6 \%)$ & $\begin{array}{l}0,018^{*} \\
0,029^{\#}\end{array}$ \\
\hline General symptoms & $17(38.6 \%)$ & $13(41.9 \%)$ & $8(66.6 \%)$ & 0.132 \\
\hline Fever & $5(11.4 \%)$ & $3(9.7 \%)$ & $6(50 \%)$ & $0.005^{\text {*\# }}$ \\
\hline
\end{tabular}

SD: standard deviation. ESR: erythrocyte sedimentation rate. CRP: C reactive protein. PMR: polymyalgia rheumatica.

*Statistically significant difference between cranial pattern and large vessel pattern.

"Statistically significant difference between mixed pattern and large vessel pattern.

Conclusion: Imaging in GCA allow us to establish different patterns of involvement (cranial, mixed, large vessel) that correspond to different clinical subsets. The patients with LV subset debut with a lower ESR and have more fever and polymyalgia rheumatica and less ischemic symptoms.

References:

[1] van der Geest KSM, Sandovici M, van Sleen Y, et al. Review: What Is the Current Evidence for Disease Subsets in Giant Cell Arteritis?. Arthritis Rheumatol. 2018;70(9):1366-1376. doi:10.1002/art.40520

Disclosure of Interests: : Elisa Fernández: None declared, Irene Monjo: None declared, Gemma Bonilla: None declared, Diana Peiteado: None declared, Chamaida Plasencia: None declared, Alejandro Balsa Grant/research support from: BMS, Roche, Consultant of: AbbVie, Gilead, Lilly, Pfizer, UCB, Sanofi, Sandoz, Speakers bureau: AbbVie, Lilly, Sanofi, Novartis, Pfizer, UCB, Roche, Nordic, Sandoz, Eugenio de Miguel Grant/research support from: Yes (Abbvie, Novartis, Pfizer) Consultant of: Yes (Abbvie, Novartis, Pfizer), Paid instructor for: yes (AbbVie, Novartis, Pfizer, MSD, BMS, UCB, Roche, Grunental, Janssen, Sanofi), Speakers bureau: yes (AbbVie, Novartis, Pfizer, MSD, BMS, UCB, Roche, Grunental, Janssen, Sanofi) DOI: 10.1136/annrheumdis-2020-eular.2589

\section{$\mathrm{AB} 0477$ OVARIAN RESERVE IN PATIENTS WITH RHEUMATIC DISEASES}

Z. Alekberova', R. Goloeva ${ }^{1}$, M. Cherkasova ${ }^{1}$, A. Lila' ${ }^{1}{ }^{1}$ V.A. Nasonova Research Institute of Rheumatology, Moscow, Russian Federation

Background: Access to assays of circulating anti-Mullerian hormone (AMH) levels has opened a new page in the assessment of ovarian function and fertility in various diseases, including rheumatic diseases (RDs). The definition of AMH as a marker of ovarian reserve significantly simplified its interpretation as well as measuring the contribution of the disease itself to the patients' infertility. 